THE INFLUENCE OF SELF-PERCEPTIONS OF AGING ON COGNITIVE FUNCTIONING IN OLDER ADULT DYADS

A Thesis
presented to
the Faculty of the Graduate School
at the University of Missouri-Columbia
In Partial Fulfillment
of the Requirements for the Degree
Master of Science
by
HANAMORI F. SKOBLOW
Dr. Christine M. Proulx, Thesis Supervisor
MAY 2021


The undersigned, appointed by the dead of the Graduate School, have examined the thesis entitled

\section{THE INFLUENCE OF SELF-PERCEPTIONS OF AGING ON COGNITIVE FUNCTIONING IN OLDER ADULT DYADS}

presented by Hanamori F. Skoblow, a candidate for the degree of Master of Science, and hereby certify that, in their opinion, it is worthy of acceptance.

Associate Professor Christine M. Proulx

Associate Professor Jacquelyn J. Benson

Assistant Professor Erin L. Robinson 


\section{DEDICATION}

This thesis, and all my progress to this point, is thanks to my wonderful parents. Thank you for raising me to love learning and literature, to look at the world with a curious and skeptical eye, and to never compromise a good night's sleep. Thank you for reminding me that productivity and inspiration are cultivated by time spent thinking under a tree or walking through the woods, rather than staring at a computer. Thank you for making me a more compassionate and empathetic person. I am, as always, endlessly grateful that you are my parents.

To Jared, my partner and my person. You have engaged in more conversations about nonindependence, model fit, and parameter estimates than you ever wanted, but you have always held space for me to process this project aloud with you. When I have found myself in the weeds, you have helped me to see the forest. Thank you for keeping me grounded and balanced. Thank you for reminding me who I am outside of graduate school. Thank you for pretending to be impressed when I show you my syntax. I am continually and profoundly grateful to know you. 


\section{ACKNOWLEDGMENTS}

They say it takes a village to write a thesis (or something like that) and many scholars have supported me throughout this process. Thank you to Drs. Jacquelyn Benson and Erin Robinson for serving on my committee. Your questions, advice, and direction have been invaluable in strengthening this project. I am grateful for your flexibility and willingness to help me even in the midst of a pandemic and I hope we are able to meet outside of a Zoom room one day soon. Thank you also to Drs. Ashley Ermer and Erin Lavender-Stott for reading early drafts of this manuscript and providing questions and guidance. Thank you to Drs. Jordan Arellanes, Jennifer Doty, and the rest of our NCFR writing group for helping me set and meet my writing goals.

Above all, I am deeply grateful to my advisor and mentor, Dr. Christine Proulx. Thank you for your excitement about this idea in its early days, for your explanations of the nuances of dyadic data, for your encouragement as I added words to page, and everything in between. It is not an exaggeration to say that this project would not have been possible without your knowledge, feedback, affirmation, and Mplus trouble-shooting ability. Thank you for your dedication to my growth as an early researcher. 


\section{TABLE OF CONTENTS}

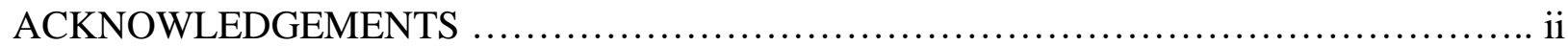

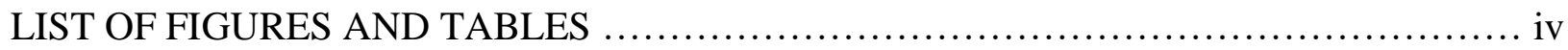

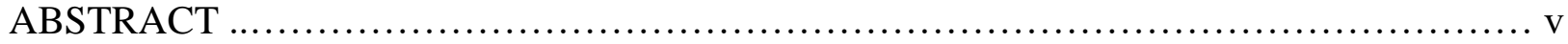

Chapter

1. INTRODUCTION AND LITERATURE REVIEW ............................. 1

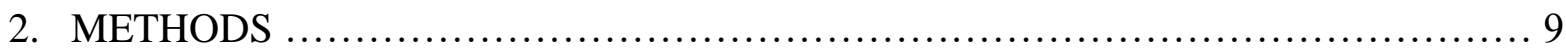

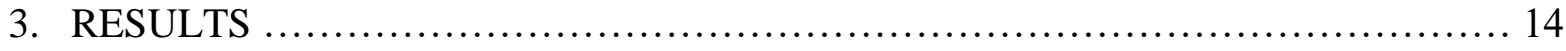

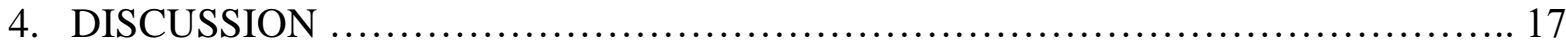

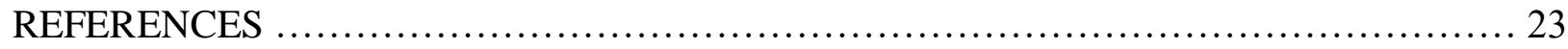

APPENDIX A: FIGURES AND TABLES ......................................... 34 


\section{LIST OF FIGURES AND TABLES}

Figure $\quad$ Page

1. Actor-Partner Interdependence Model ....................................... 34

Table

1. Participant Demographic Characteristics ...................................... 35

2. Correlations Between Self-Perceptions of Aging, Episodic Memory, and Self-Rated

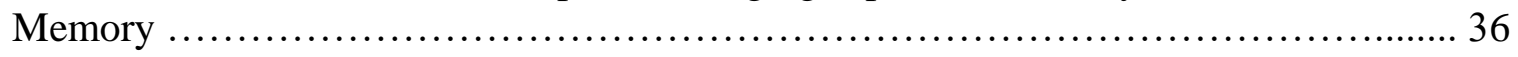

3. Results of Actor-Partner Interdependence Models ................................ 38 


\title{
THE INFLUENCE OF SELF-PERCEPTIONS OF AGING ON COGNITIVE FUNCTIONING IN OLDER ADULT DYADS
}

\author{
Hanamori F. Skoblow \\ Dr. Christine M. Proulx, Thesis Supervisor
}

\begin{abstract}
Older adults who report negative self-perceptions of aging (SPA) perform worse on memory tests and perceive their memory abilities to be worse than their counterparts who report positive SPA. Research suggests that romantic partners influence one another's experience and appraisal of aging. Thus, this study examined whether individuals' SPA impacted their own and their partner's memory longitudinally. Using three waves of data from the Health and Retirement Study (HRS), we conducted actor-partner interdependence models with 933 married or cohabiting couples aged 50 to 88 to determine whether positive and negative dimensions of SPA influenced change in episodic memory (i.e., immediate and delayed recall) and self-rated memory over eight years. Partners' SPA were positively correlated at baseline (positive $=.393, p$ $<.001$; negative $=.441, p<.001)$, however, we did not find evidence that SPA was associated with change in episodic or self-rated memory in either the actor or the partner. These findings indicate that individuals' SPA is related to their partners', but researchers should continue to investigate the degree to which social influences of SPA impact cognitive functioning in older adulthood.
\end{abstract}




\section{CHAPTER 1: INTRODUCTION AND LITERATURE REVIEW}

Self-perceptions of aging (SPA) — or attitudes towards one's own aging processtranscend psychological well-being and impact other aspects of late-life health. Research demonstrates the predictive power of SPA on a variety of health outcomes, including longevity (Levy et al., 2002), physical functioning (Levy, Slade, et al., 2012; Tovel et al., 2019), preventative health behaviors (Levy \& Myers, 2004), and cognitive functioning (Levy et al., 2016; Robertson \& Kenny 2016a; Robertson \& Kenny, 2016b). Collectively, the literature demonstrates that negative SPA may exacerbate health problems, whereas positive SPA may be protective, even against normative age-related decline. One area of potential decline that is concerning to both older adults and their loved ones is cognitive functioning. Although cognitive functioning is often considered at the individual level, it is strongly influenced by adults' social context, including marital relationships. Despite evidence documenting the effect of SPA on older adults' cognitive functioning, we know of no research into this phenomenon within older adult dyads.

When couples reminisce about their shared histories, some partners employ facilitating or hindering strategies that may positively or negatively impact one another's memory abilities (Harris et al., 2011). Older adults who describe past events together recall more details than their counterparts who remember alone (Barnier et al., 2014). Additionally, past work demonstrates that one spouse's internal beliefs may influence the other's memory (Oh et al., 2019), one spouse's SPA can contribute to the other's well-being (Momtaz et al., 2013), and one spouse's SPA can influence the other's over time (Cohn-Schwartz et al., 2020). Taken together, it may be that an individual's SPA, an internal belief, has the capacity to impact their own and a spouse's memory. Thus, the purpose of this study is to extend the literature on the effects of self- 
perceptions of aging on episodic and self-rated memory among married and partnered older adults within an actor-partner interdependence framework (APIM; Kenny et al., 2006). The APIM framework allows for the simultaneous evaluation of within-person influence (i.e., actor effects) and spousal influence (i.e., partner effects).

\section{Cognitive Functioning and Decline}

Cognitive decline is influenced by lifestyle factors, physical and mental health, and socioeconomic status (Beydoun et al., 2014). Cognitive decline may begin as early as age 50 (Gerstorf et al., 2011), but between-person variability is high (Wilson et al., 2020) and the average age of cognitive impairment is much later-ages 70 for men and 73 for women (Hale et al., 2020). Greater stability in cognitive functioning is influenced by a variety of factors, including education, race, and ethnicity, highlighting social inequities: Older adults with marginalized identities are more likely to experience an earlier onset of cognitive decline than their more advantaged counterparts, who tend to experience cognitive decline later but more rapidly (Hale et al., 2020).

Despite substantial heterogeneity in trajectories of cognitive functioning (Wilson et al., 2020), research consistently demonstrates some predictable patterns in context-specific memory loss. Specifically, greater age is associated with declines in episodic memory, or remembering lived experiences. Evidence from fMRI analyses indicate more dedifferentiation in older adults' brain activity compared to younger adults. This decrease in region specialization may be a compensatory, although less effective, memory technique (St-Laurent et al., 2011). Episodic memory is key not only to remembering past events, but also speculating about the future. Research shows that a decrease in episodic memory is associated with a decrease in imagining future scenarios based on a reconfiguration of previous experiences (Addis et al., 2008). By 
contrast, vocabulary and semantic memory, or remembering factual information, tend to stay stable or improve with age (St-Laurent et al., 2011). When recalling past events, older adults describe fewer episodic elements and more semantic elements than younger adults (Addis et al., 2008; Levine et al., 2002).

Evidence suggests that cognitive decline is not solely an intraindividual process, but may be influenced by close relationships, as spouses' cognitive abilities tend to be concordant (Gruber-Baldini et al., 1995). Spousal influences may be experienced differently, such that men's cognitive function exerts greater influence on their wives' health than vice versa. Past work has found that husbands' cognitive decline predicts similar outcomes in wives, although the reverse is not significant (Gerstorf et al., 2009; Strawbridge et al., 2011). However, both spouses benefit from collaborative recall. Older couples' episodic memory improves when they recall past events together, although recall still underperforms compared with younger couples (Barnier et al., 2014).

\section{Theoretical and Empirical Foundations}

The present study is guided by two theories: stereotype embodiment (Levy, 2009) and interdependence (Rusbult \& Van Lange, 2003). The former describes the formation and manifestation of SPA in the individual while the latter describes how these internal beliefs may impact the individual's spouse. Together, these theories provide a potential mechanism through which societal norms are internalized as beliefs and then externalized to influence significant others.

\section{Stereotype Embodiment Theory}

According to stereotype embodiment theory, self-perceptions of aging are developed from societal and interpersonal constructions of aging encountered across the life course (Levy, 
2009). Age-based stereotypes are oversimplified generalizations of age groups formed early in life; when shown drawings of older men, children as young as 3-years-old report age-based stereotypes (Seefeldt et al., 1977). Ultimately, individuals carry these beliefs with them as they enter old age themselves, at which point these stereotypes become self-relevant and are referred to as SPA (Levy, 2009). When triggered implicitly, holding negative SPA may result in undesirable outcomes.

In a now-seminal experimental design, Levy (1996) demonstrated that implicitly priming older adults with negative age-related stereotypes worsens memory performance. By contrast, positive stereotype priming resulted in better performance. Notably, this study included a comparison group of young adults. Neither positive nor negative age-based stereotypes affected the younger adults, suggesting that stereotypes must be considered self-relevant to be impactful. These results have since been replicated (Hess et al., 2003).

\section{SPA and Memory Performance}

The long-term, as well as the short-term, effects of negative SPA appear to be detrimental. Levy and colleagues (2016) found that participants who held negative SPA experienced greater hippocampal volume loss and higher Alzheimer's disease pathology scores over ten years than participants with more positive SPA, despite no participants demonstrating symptoms of dementia at the start of the study. Similarly, a study examining known genetic predispositions for dementia found that holding positive SPA can protect high-risk older adults from cognitive decline (Levy et al., 2018). Other studies have found associations between more positive SPA and greater cognitive function, broadly speaking (Kleinspehn-Ammerlahn et al., 2008). Other research suggests that negative SPA is associated with lower global cognitive functioning, executive function, and memory (Robertson \& Kenny, 2016b). Moreover, the 
effects of SPA appear to be long-lasting. Longitudinal studies conducted over two (Robertson et al., 2016) and 38 years (Levy, Zonderman, et al., 2012) have found effects of baseline negative SPA on later memory decline.

Most previous research has connected SPA and episodic memory performance, often operationalized with immediate and/or delayed recall tests (Brown et al., 2020; Hess et al., 2003; Levy, 1996; Levy, Zonderman, et al., 2012; Robertson et al., 2016). However, there is variability in the procedure behind these tests. Whereas some researchers read a list of words for participants to recall verbally (Brown et al., 2020; Levy, 1996; Robertson et al., 2016), other studies allow study time and then require participants to write their responses (Hess et al., 2003). Others eschew linguistic recall entirely, opting for visuospatial recall of a pattern of dots (Levy, 1996) or geometric shapes (Levy, Zonderman, et al., 2012). Another measure gave participants a set of faces that corresponded to a hobby, then asked participants to match people with their pastimes (Levy, 1996). Because different types of recall are assessed across studies, it is difficult to compare their findings directly.

Moreover, other studies found that negative SPA was related only to older adults' subjective evaluation of memory decline, not objective indicators (Siebert et al., 2020; Sindi et al., 2012). For instance, Robertson et al. (2016) found that although negative SPA predicted selfrated memory, SPA was not associated with change in episodic memory over two years. It may be that by triggering held stereotypes about cognitive functioning and aging, SPA has a greater effect on one's perception of memory than actual memory decline. It is also possible that subjective memory represents a broader definition of change than cognitive batteries do as participants can reflect on everyday indications of memory abilities not captured by laboratory tests. Still, even the most equivocal findings indicate some impact of SPA on memory. 
Therefore, we hypothesize that an individual's SPA will predict later memory performance and perception, such that more positive SPA will be associated with less memory decline and more negative SPA will be associated with more memory decline.

\section{Interdependence Theory}

Interdependence theory posits that many processes cannot be viewed as entirely individual, as they are both intrapersonal and interpersonal (Rusbult \& Van Lange, 2003). Rather, as social animals, humans influence and are influenced by others. The strongest influences are exerted between particularly close social network members. For many of today's older adults, the majority of whom are married (Margolis \& Verdery, 2017; U.S. Census Bureau, 2010), the closest and most interdependent relationship is with a spouse. Unique features of latelife relationships may make this interdependence especially salient. Despite an increase in divorce and remarriage in later life (i.e., 'the gray divorce;' Brown \& Lin, 2012), greater longevity means married older adults have the opportunity to remain in their marriages for longer than previous cohorts (Agree \& Hughes, 2012). Retirement may also result in an increase in joint leisure activities and time spent together (Stancanelli \& Van Soest, 2016), further increasing interdependence.

Committed romantic partners are cognitively interdependent, consider themselves an intertwined unit (Agnew et al., 1998), and look to one another for cues on how to appraise a given situation (Rusbult \& Van Langue, 2003). Spouses also report similar levels of subjective well-being, including life satisfaction and meaning in life, as well as subjective health (Bookwala \& Schulz, 1996). Thus, it stands to reason that spouses' internal beliefs are concordant (Walker \& Luszcz, 2009). There is a growing interest on the social context of SPA, and studies that adopt a couple-level approach support this concordance, finding that spouses score similarly on 
measures of SPA (Cohn-Schwartz et al., 2020; Kim et al., 2018; Mejía \& Gonzales, 2017; Mejía et al., 2020; Momtaz et al., 2013). For instance, one dyadic study found that one spouse's SPA influenced the other's four years later (Cohn-Schwartz et al., 2020). Additionally, evidence suggests that older spouses craft their SPA together as they experience life and aging together (Mejía et al., 2020). Spouses also tend to experience the physical elements of aging similarly. Increasing frailty and depressive symptoms in one spouse predict these outcomes in the other spouse (Monin et al., 2016). With age, couples also exhibit similar degrees of cognitive decline (Dufouil \& Alpérovitch, 2000). Accordingly, we hypothesize that spouses' reports of SPA and memory performance will be positively associated.

\section{Internal Beliefs and Spouses' Outcomes}

Although little research has examined SPA dyadically, there is reason to investigate a possible partner effect on memory performance. Evidence suggests that individuals' internal beliefs can influence their spouse's health and well-being. For instance, spousal caregivers' beliefs about pain and control are related to their spouses' experience of chronic pain severity (Cano et al., 2009; Riley-Doucet, 2005). Additionally, having a partner who is satisfied with life is uniquely associated with higher subjective health, more frequent engagement in physical activity (Chopik \& O’Brien, 2017), and a reduced risk of mortality (Stavrova, 2019). Life satisfaction, as well as mastery, is further associated with fewer functional limitations in a partner (Chopik \& O’Brien, 2017; Drewelies et al., 2018).

Cognitive functioning is no exception to spousal influence. Having an optimistic spouse, for example, is positively associated with episodic memory (Oh et al., 2019). In some circumstances, cognitive functioning is also related to a spouse's perceived social status (Zhang et al., 2019). Particularly relevant to the current hypotheses, preliminary evidence suggests 
individuals' SPA affects their spouses' well-being. In a study of 300 married dyads, Malaysian older adults' positive or negative SPA predicted their spouse's psychological well-being (Momtaz et al., 2013). These findings were consistent among both husbands and wives. Not only is psychological well-being important in its own right, it may also be associated with cognitive functioning (Zank \& Leipold, 2001). Thus, our final hypothesis is that an individual's SPA will predict their spouse's later memory performance, such that more positive SPA in an individual will be associated with less memory decline in the spouse, and more negative SPA in an individual will be associated with more memory decline in the spouse.

\section{The Present Study}

The present study extends prior research by examining the impact of self-perceptions of aging on change in cognitive functioning within the marital dyad over eight years. In light of the theoretical framework and empirical evidence, we tested the following hypotheses: (a) partners' self-perceptions of aging will be significantly correlated; (b) there will be an actor effect such that more positive self-perceptions of aging will be associated with less memory decline over a period of eight years; and (c) there will be a partner effect, such that more positive selfperceptions of aging in the partner will be associated with less memory decline in the actor, above and beyond the actor effects. 


\section{CHAPTER 2: METHODS}

\section{Participants}

The sample included spouses aged 50 to 88 in different-sex marriages and cohabitations from the Health and Retirement Study (HRS), a nationally representative longitudinal study of older adults in the United States conducted biennially since 1992. Every four years since 2006, 50 percent of the HRS sample has been eligible to complete a leave-behind questionnaire (LBQ) of psychosocial measures, including SPA, which was added to the LBQ in 2008. Therefore, we drew our sample from those respondents who completed the LBQ in 2008. The response rate for 2008 was $83.7 \%$ of all eligible respondents (Smith et al., 2017). Past work shows that couples who were eligible for the LBQ but did not complete it reported, on average, less positive health and more depressive symptoms than those who did (Cohn-Schwartz et al., 2020). The most recent wave of HRS LBQ data publicly available at the time of these analyses was collected in 2016. Therefore, we will examine the association between baseline SPA in 2008 and change in memory from 2008 to 2016.

To create the analytic sample, we first excluded all participants who were not in a partnered couple, for a sample of 5,533. Next, we excluded participants who did not complete the LBQ, for a sample of 2,317. Some participants completed the HRS core survey and the LBQ, but their spouses had either not participated in the HRS at all or declined to complete the LBQ. Thus, we removed all individuals with non-response spouses, for a sample of 1,019 dyads (2,038 individuals). We were left with a small number $(n=16)$ of same-sex couples. Because gender was of interest and the APIM does not allow for simultaneous modeling of distinguishable and indistinguishable dyads, we excluded same-sex couples from analysis. To increase validity of the analyses, we excluded all dyads in which at least one spouse did not complete three or more 
items in the eight-item SPA scale $(n=30)$ or used a proxy respondent in the cognitive functioning measures $(n=6)$. Finally, we excluded all dyads in which one spouse was absent $(n$ $=4)$ or was under 50 years old $(n=48)$. One household contained two couples and we randomly excluded one couple to avoid possible contamination issues. The final sample of different-sex married (97\%) or cohabiting (3\%) couples aged 50 and over who completed the target measures is $n=933$ dyads (1,866 individuals).

\section{Measures}

\section{Memory}

A total of two measures were used to assess memory in both 2008 and 2016. The first assessed episodic memory with two 10-word immediate and delayed recall tasks (Ofstedal et al., 2005). Possible scores range from 0 to 20 with each point indicating one recalled word. Some studies have not found significant associations between SPA and objective measures of cognitive functioning, but rather significant associations with subjective measures (Robertson et al., 2016; Siebert et al., 2020). Accordingly, our second measure is a single item assessing self-rated memory: "How would you rate your memory at the present time?" Responses range from 1 (poor) to 5 (excellent). We excluded measures of crystallized intelligence-learned knowledge and facts, which HRS operationalizes as vocabulary — as these may be more indicative of educational attainment than cognitive functioning, and hence, may result in overstated differences across socioeconomic status (Ghisletta et al., 2012).

\section{Self-perceptions of Aging}

HRS assessed SPA in 2008 with eight items, five from the Philadelphia Geriatric Center Morale Scale (Lawton, 1975; Liang \& Bollen, 1983) and three from the Berlin Aging Study (https://www.base-berlin.mpg.de/en). The latter three items were added to ensure an equal 
number of items correspond to the negative and positive dimensions of subjective aging, creating a scale unique to the HRS. Exploratory factor analyses (EFA) revealed that a two-factor (i.e., one positive, one negative) representation of SPA was more optimal than a unidimensional scale.

Additionally, we removed one item ("I have as much pep as I did last year") due to low correlations with other items. Thus, in this study, three items assess positive SPA (e.g., "So far, I am happy with the way that I am aging”) and four items assess negative SPA (e.g., "Things keep getting worse as I get older"). Answers range from 1 (strongly disagree) to 6 (strongly agree) with higher scores representing more positive or negative SPA, respectively.

Previous research has shown strong construct validity with the HRS SPA measures and other scales of internal beliefs and well-being. Giasson (2017) found positive correlations between the positive dimension of SPA and positive affect, life satisfaction, life purpose, perceived mastery, perceived control over health, and optimism, demonstrating good convergent validity. The negative dimension of SPA was positively correlated with negative affect, perceived constraints on control, and pessimism, demonstrating good divergent validity. With the present analytic sample, there was good internal consistency for both the positive (men $\alpha=.77$; women $\alpha=.79$ ) and negative (men $\alpha=.78$; women $\alpha=.78$ ) dimensions. The correlations between these scales were $r=-.44$ for men and $r=-.44$ for women.

\section{Covariates}

We controlled for several variables that have been associated with cognitive functioning (Hale et al., 2020). Age and education were entered as continuous variables in years. Race (88\% white, $7 \%$ Black, $5 \%$ other) and ethnicity (10\% Hispanic, 90\% non-Hispanic) were dummycoded and entered as categorical variables. Following Smith and Larkina (2020), we also controlled for financial resources by computing quintiles of the couple's household wealth. 
Constructed by the RAND Corporation, a non-profit research institution, based on multiple HRS variables, sources of wealth in this measure include, but are not limited to, property value, savings, stocks, and bonds. Outstanding debts are deducted from household wealth, occasionally resulting in a negative assets score. The first and lowest quintile ranges from $\$ 550,000$ in debt to $\$ 100,820$ in assets; the fifth and highest quintile ranges from $\$ 1,024,200$ to $\$ 37,050,000$ in assets. Self-rated health is strongly correlated with cognitive decline (Bond et al., 2006), therefore we controlled for this variable at baseline $(1=$ poor, $5=$ excellent $)$. Finally, we controlled for depressive symptoms with the summed RAND scale derived from an eight-item short form of the Center for Epidemiological Studies Depression Scale (CES-D; Radloff, 1977) in which higher scores represent more depressive symptoms. Depressive symptoms have been associated with cognitive functioning in previous research (McEwen, 2017).

\section{Analytic strategy}

We conducted descriptive analyses with paired $t$-tests to determine whether differences between spouses existed, as well as whether there were within-person differences between 2008 and 2016. To test our primary hypotheses, APIMs (Kenny et al., 2006) were computed with structural equation modeling (SEM) in Mplus version 8 (Muthén \& Muthén, 1998-2017). The APIM allows one to model individual and dyadic effects simultaneously. In this case, we estimated the degree to which one's own positive and negative SPA are associated with one's own and partner's change in memory over time. Both positive and negative dimensions of SPA were included in the same models and two separate models were computed to estimate the change in objective and subjective memory. This conceptual model is presented in Figure 1.

Change in memory from 2008 to 2016 was modeled as a difference score as this method is more accurate than residualized scores when using nonrandomized data (Castro-Schilo \& 
Grimm, 2018). Although we considered modeling episodic memory as a latent variable, only two measures (immediate and delayed recall) are available in the HRS and scholars recommend including at least three indicators with latent variable modeling (Kenny et al., 2006). 


\section{CHAPTER 3: RESULTS}

\section{Descriptive Analyses}

Paired $t$-tests (see Table 1) revealed that the men in this sample were significantly older and more educated than the women and reported significantly fewer depressive symptoms and higher negative SPA than did women. In the episodic memory tasks, women recalled significantly more words than men did, both at baseline and eight years later. However, men and women did not significantly differ on self-rated health at baseline or on self-rated memory at either time point. We also conducted paired $t$-tests to examine within-person change in memory from 2008 to 2016 . Results indicated that women recalled significantly more words in $2008(M=$ 11.47; $S D=2.90)$ than they did in $2016(M=10.19 ; S D=3.06), t(902)=13.55, p<.001, d$ $=.45$. Similarly, there was a significant decline in men's recall from $2008(M=9.96 ; S D=2.95)$ to $2016(M=8.71 ; S D=3.18), t(883)=13.18, p<.001, d=.44$. Women also rated their memories as significantly better in $2008(M=3.11 ; S D=.89)$ compared with their responses in $2016(M=2.92 ; S D=0.88), t(902)=6.81, p<.001, d=.23$. Consistent with their partners, there was a significant decline in men's perception of their memories from $2008(M=3.11 ; S D=0.93)$ to $2016(M=2.84 ; S D=.93), t(883)=8.91, p<.001, d=.30$.

Bivariate correlations for positive and negative SPA, episodic memory, and self-rated memory are presented in Table 2. Men and women's positive SPA was associated with their own self-rated memory at both time points, but not their partner's, nor was it associated with their own or their partner's episodic memory at either time point. Men's negative SPA was associated with his and his partners' episodic and self-rated memory at both time points. Women's negative SPA was associated with all variables except for her partner's self-rated memory at the second 
time point. All memory variables were significantly correlated both within-person and betweenpartners.

\section{Dyadic Analyses}

We used full information maximum likelihood to address missing data and assessed model fit with chi square $\left(\chi_{2}\right)$, comparative fit index $(\mathrm{CFI})$, root mean square error of approximation (RMSEA), and standardized root mean square residual (SRMR; Hu \& Bentler, 1999). Acceptable model fit values are .95 or above for CFI, .06 or below for RMSEA, and .08 or below for SRMR.

\section{Episodic memory}

We first examined whether own and partner's SPA predicted the difference in own and partner's episodic memory over eight years (see Table 3). The basic APIM without covariates showed poor model fit to the data $\left(\chi^{2}(0)=1.00, p<.001, \mathrm{CFI}=0, \operatorname{RMSEA}=0[\mathrm{CI}(0,0)]\right.$, SRMR = 0; Hu \& Bentler, 1999). In accordance with the first hypothesis, partners' positive SPA were correlated at $.39(p<.001)$ and their negative SPA were correlated at $.44(p<.001)$. The second and third hypotheses were not supported, however, as SPA was unrelated to change in episodic memory.

The second model, in which we controlled for age, education, race, ethnicity, wealth, self-rated health, and depressive symptomology, showed poor model fit $\left(\chi^{2}(144)=1.03, p\right.$ $<.001, \mathrm{CFI}=0, \mathrm{RMSEA}=.07$ [CI (.06, .07)], SRMR = .09; Hu \& Bentler, 1999). Partners’ positive SPA were significantly correlated at $.38(p<.001)$ and their negative SPA were significantly correlated at $.43(p<.001)$, supporting the first hypothesis. Contrary to the second and third hypotheses, neither the actor's nor the partner's SPA was significantly associated with change in episodic memory. 


\section{Self-rated memory}

We then examined whether own and partner's SPA predicted change in own and partner's self-rated memory over eight years. The basic model without covariates showed mixed model fit to the data $\left(\chi^{2}(0)=1.00, p<.001, \mathrm{CFI}=1.00, \mathrm{RMSEA}=0[\mathrm{CI}(0,0)], \mathrm{SRMR}=0 ; \mathrm{Hu}\right.$ \& Bentler, 1999). The first hypothesis was supported as partners' positive SPA were correlated at $.39(p<.001)$ and their negative SPA were correlated at $.44(p<.001)$. The second and third hypotheses were not supported, however, as SPA was unrelated to change in self-rated memory. Adding covariates to the second model resulted in poor model fit $\left(\chi^{2}(144)=1.05, p\right.$ $<.001, \mathrm{CFI}=0, \mathrm{RMSEA}=.07[\mathrm{CI}(.06, .07)], \mathrm{SRMR}=.09 ; \mathrm{Hu} \&$ Bentler, 1999). In support of the first hypothesis, we found significant within-couple correlations between partners' positive $(r$ $=.38, p<.001)$ and negative SPA $(r=.43, p<.001)$. However, we did not find evidence supporting the second and third hypotheses as neither the actor's nor the partner's SPA was significantly associated with change in self-memory. 


\section{CHAPTER 4: DISCUSSION}

Researchers increasingly agree that internal beliefs and close relationships influence how adults experience aging (Mejía et al., 2020). Informed by stereotype embodiment theory and interdependence theory, we implemented a dyadic framework in examining the influence of positive and negative dimensions of SPA on change in own and partner's objective and subjective memory. In a large, nationally representative sample of middle-age and older adults, we found evidence that partners' reports of positive and negative SPA were positively correlated. These findings are consistent with past work suggesting that partners tend to report similar levels of SPA (Cohn-Schwartz et al., 2020; Kim et al., 2018; Mejía \& Gonzales, 2017; Momtaz et al., 2013). Whether this similarity is due to selection effects prior to partnership or whether partners become increasingly similar by spending time together as they age was beyond the scope of this study, although other researchers have found that couples with the longest marital duration report the greatest concordance in their beliefs about aging (Mejía et al., 2020). Evidence from relationship science and interdependence theory suggest that individuals often select partners with similar characteristics, become more similar in the early part of a relationship, and then maintain this level of similarity over the course of their partnership (Caspi et al., 1992; Gonzaga et al., 2007). However, research on subjective aging suggests that own SPA influences a partner's SPA longitudinally (Cohn-Schwartz et al., 2020). These findings, and ours, support interdependence theory as adults' experiences of aging are related to their partners' appraisal of and satisfaction with growing older (Rusbult \& Van Lange, 2003). Thus, it may be that partners in middle and older adulthood experience a convergence of SPA.

Despite the evidence demonstrating within-couple SPA correlations, we did not find evidence for the hypotheses that participants' own SPA influenced their or their partners' 
declines in memory abilities or perceptions of memory over time. It is possible that these null findings are the result of a relatively short period (i.e., eight years) between data collections. Although participants' memories significantly declined between time points, the difference in scores was small. Both men $(M=1.25 ; S D=2.83)$ and women $(M=1.28 ; S D=2.83)$ recalled about one fewer word between the 2008 and 2016 waves of data collection. The mean difference score in self-rated memory for men was .27 $(S D=.91)$ and for women was .19 $(S D=.84)$, indicating minimal change in subjective memory assessment. Although some participants' difference scores are more extreme, the majority of participants did not experience or report much change in memory. Our inclusion criteria may be germane as well. First, the sample included participants in midlife who may not experience or perceive as much cognitive decline over an eight-year period as their older counterparts might. In addition, the majority of participants were White, non-Hispanic, and had obtained a high school degree, characteristics that are associated with later onset of cognitive impairment compared to people of color and less educated adults (Hale et al., 2020). Lastly, in order to increase validity, we excluded couples in which one partner used a proxy respondent $(n=6)$ to complete the cognitive measures. However, participants with the greatest cognitive impairment are most likely to require assistance during data collection and including these participants in the analyses may have resulted in a greater distribution of change in memory performance and perception. In sum, there are a variety of possible reasons behind the little variability in the outcome measures.

The measures used to assess the predictors, as well as the outcomes, may have contributed to our lack of dyadic findings. There are multiple measures of SPA which may produce different results, although none are available in the HRS. As indicated by the results of our EFA, SPA is comprised of related, but distinct dimensions. In our study, we examined 
positive and negative dimensions, but other scales that move beyond valence may provide additional insight. For instance, the Aging Related Cognitions (AgeCog) scales represent four domain-specific factors of SPA: physical decline, social loss, ongoing development, and selfknowledge and control. Created by Steverink et al. (2001), the AgeCog scales are used with increasing frequency, although few studies incorporate all four scales, typically using the physical decline scale or separating by positive and negative valence (Boeder \& Tse, 2020). To capture directionality and domain-specificity in SPA, Brothers et al. (2019) developed the Awareness of Age-Related Change (AARC) scale which assesses perceived gains and losses across five domains: health and physical functioning; cognitive functioning; interpersonal relations; social-cognitive and social-emotional functioning; and lifestyle and engagement. The AARC is unique in its ability to capture positive and negative perceptions across each domain. Given its newness, this measure has yet to be used widely. Recently, Kornadt et al. (2020) created three brief measures of subjective aging: age stereotypes, future selves, and age-related preparation. To our knowledge, no studies have utilized these brief measures to date. Others have operationalized SPA as a combination of aging anxiety and future time perspective (e.g., Kim et al., 2018). Future research should explore whether domain-specific aspects of SPA shape trajectories of memory in middle and older adulthood.

Beyond variability in this sample, there may be other psychosocial variables that contribute to change in memory. We attempted to include covariates that would explain a significant portion of the variance in these models, such as depressive symptomology and selfrated health. However, we acknowledge that the social determinants of cognitive functioning are varied and complex. Other variables similar to SPA that may influence memory abilities include optimism (Oh et al., 2019), life satisfaction (Zank \& Leipold, 2001), and life purpose (Lewis et 
al., 2016). Therefore, researchers might want to examine the impact of other forms of well-being and adjustment on change in memory in a dyadic context.

\section{Limitations and Future Directions}

Despite the strengths of this study_-including a large sample size, the use of longitudinal data, and a bidimensional measure of SPA — there are some limitations which we would be remiss to ignore. First, our analyses do not account for potential bidirectional effects. That is, it is plausible that observing cognitive decline in oneself or one's partner triggers held age stereotypes, resulting in more negative SPA. Indeed, research suggests that SPA is socially constructed as adults compare their own aging to their perception of others' aging to determine what constitutes normative versus non-normative aging (Kleinspehn-Ammerlahn et al., 2008; Sargent-Cox et al., 2012). Correspondingly, noticeable changes in health are more salient on partner's SPA than invisible or internal changes (Mejía et al., 2020). From the perspective of stereotype embodiment theory, it may be that a noticeable degree of cognitive decline triggers internal beliefs about age-related cognitive impairment and dependency, which is related to more negative SPA, and in turn, results in greater cognitive decline. Accordingly, future research may want to revisit this topic over a longer period when evidence of cognitive change is more likely.

Additionally, we were unable to include the small number of same-sex couples $(n=16)$ in these analyses as the APIM does not allow for simultaneous modeling of distinguishable and indistinguishable dyads. As such, same-sex couples would need to be included in a separate model, but SEM requires samples of at least 100 dyads for sufficient power to avoid committing a Type II error (Kline, 2016). Although lesbian, gay, and bisexual (LGB) older adults have been underrepresented in the gerontological literature to date, evidence suggests that managing two marginalized identities (i.e., LGB and older adult) may influence one's experience of aging 
(Fredriksen-Goldsen \& Muraco, 2010). The chronic stress associated with repeated discrimination may impact the brain's production of cortisol, which can impair memory performance (Lupian et al., 2009; Miller et al., 2007). Thus, we recommend that future research in this area recruit older adults in same-sex relationships.

Finally, many respondents who were eligible to complete the LBQ declined to do so. As others using these data have found, participants who completed the LBQ reported fewer depressive symptoms and better health than those who did not complete the questionnaire (CohnSchwartz et al., 2020). Because memory ability is related to physical and mental health (Jajodia \& Borders, 2011), it is possible that these data do not fully capture the experiences of partnered older adults, but rather overrepresent those who are healthier and happier than average. Other researchers may want to explore how these findings generalize to populations who have been diagnosed with chronic diseases or clinical disorders.

\section{Conclusion}

To the best of our knowledge, this study is the first to examine whether SPA is associated with change in memory performance and perceptions in dyads. We build on studies demonstrating that SPA may be associated with cognitive functioning in older adults (e.g., Levy, 1996, Levy et al., 2012) and that partners may influence one another's aging perceptions and trajectories (Cohn-Schwartz et al., 2020; Mejía et al., 2020). Our findings contribute to our understanding of the complex relation between subjective aging and cognitive functioning by demonstrating that adults' positive and negative SPA may not affect own or partner's memory performance or perceptions over an eight-year period. Generating knowledge about the impact of SPA on cognitive functioning — as well as the limitations of this construct—aids in the creation 
of realistic and achievable interventions designed to modify adults' SPA, thereby promoting health and well-being. 


\section{REFERENCES}

Addis, D. R., Wong, A. T., \& Schacter, D. L. (2008). Age-related changes in the episodic simulation of future events. Psychological Science, 19(1), 33-41. https://doi.org/10.1111/j.1467-9280.2008.02043.x

Agnew, C. R., Van Lange, P. A. M., Rusbult, C. E., \& Langston, C. A. (1998). Cognitive interdependence: Commitment and the mental representation of close relationships. Journal of Personality and Social Psychology, 74(4), 939-954. https://doi.org/10.1037/0022-3514.74.4.939

Agree, E. M. \& Hughes, M. E. (2012). Demographic trends and later life families in the 21st century. In R. Bliezner \& V. H. Bedford (Eds.), Handbook of Families and Aging (2nd ed., pp. 9-33). Praeger/ABC-CLIO.

Barnier, A. J., Priddis, A. C., Broekhuijse, J. M., Harris, C. B., Cox, R. E., Addis, D. R., Keil, P. G., \& Congleton, A. R. (2014). Reaping what they sow: Benefits of remembering together in intimate couples. Journal of Applied Research in Memory and Cognition, 3(4), 261-265. https://doi.org/10.1016/j.jarmac.2014.06.003

Beydoun, M. A., Beydoun, H. A., Gamaldo, A. A., Teel, A., Zonderman, A. B., \& Wang, Y. (2014). Epidemiologic studies of modifiable factors associated with cognition and dementia: Systematic review and meta-analysis. BMC Public Health, 14(1), 643. https://doi.org/10.1186/1471-2458-14-643

Boeder, J., \& Tse, D. C. K. (2020). Measuring self-perceptions of aging: Differences between measures when predicting health outcomes. The Journals of Gerontology: Series B, gbaa064. https://doi.org/10.1093/geronb/gbaa064 
Bookwala, J., \& Schulz, R. (2000). A comparison of primary stressors, secondary stressors, and depressive symptoms between elderly caregiving husbands and wives: The caregiver health effects study. Psychology and Aging, 15(4), 607-616.

Brothers, A., Gabrian, M., Wahl, H.-W., \& Diehl, M. (2019). A new multidimensional questionnaire to assess awareness of age-related change (AARC). The Gerontologist, 59(3), e141-e151. https://doi.org/10.1093/geront/gny006

Brown, K. E., Kim, J., Stewart, T., Fulton, E., \& McCarrey, A. C. (2020). Positive, but not negative, self-perceptions of aging predict cognitive function among older adults. The International Journal of Aging and Human Development, 1-19. https://doi.org/10.1177/0091415020917681

Brown, S. L., \& Lin, I.-F. (2012). The gray divorce revolution: Rising divorce among middleaged and older adults, 1990-2010. The Journals of Gerontology Series B: Psychological Sciences and Social Sciences, 67(6), 731-741. https://doi.org/10.1093/geronb/gbs089

Cano, A., Miller, L. R., \& Loree, A. (2009). Spouse beliefs about partner chronic pain. The Journal of Pain, 10(5), 486-492. https://doi.org/10.1016/j.jpain.2008.11.005

Caspi, A., Herbener, E. S., \& Ozer, D. J. (1992). Shared experiences and the similarity of personalities: A longitudinal study of married couples. Journal of Personality and Social Psychology, 62(2), 281-291. https://doi.org/10.1037/0022-3514.62.2.281

Castro-Schilo, L., \& Grimm, K. J. (2018). Using residualized change versus difference scores for longitudinal research. Journal of Social and Personal Relationships, 35(1), 32-58. https://doi.org/10.1177/0265407517718387 
Chopik, W. J., \& O’Brien, E. (2017). Happy you, healthy me? Having a happy partner is independently associated with better health in oneself. Health Psychology, 36(1), 21-30. https://doi.org/10.1037/hea0000432

Cohn-Schwartz, E., Segel-Karpas, D., \& Ayalon, L. (2020). Longitudinal dyadic effects of aging self-perceptions on health. The Journals of Gerontology: Series B, gbaa082. https://doi.org/10.1093/geronb/gbaa082

Drewelies, J., Chopik, W. J., Hoppmann, C. A., Smith, J., \& Gerstorf, D. (2018). Linked lives: Dyadic associations of mastery beliefs with health (behavior) and health (behavior) change among older partners. The Journals of Gerontology: Series B, 73(5), 787-798. https://doi.org/10.1093/geronb/gbw058

Dufouil, C., \& Alpérovitch, A. (2000). Couple similarities for cognitive functions and psychological health. Journal of Clinical Epidemiology, 53(6), 589-593. https://doi.org/10.1016/S0895-4356(99)00189-4

Fredriksen-Goldsen, K. I., \& Muraco, A. (2010). Aging and sexual orientation: A 25-year review of the literature. Research on Aging, 32(3), 372-413. https://doi.org/10.1177/0164027509360355

Giasson, H. (2017). Self-perceptions of aging and activity engagement: Linking positive and negative appraisals to behavior. [Doctoral dissertation, University of Michigan]. Deep Blue. http://hdl.handle.net/2027.42/138787

Gerstorf, D., Hoppmann, C. A., Anstey, K. J., \& Luszcz, M. A. (2009). Dynamic links of cognitive functioning among married couples: Longitudinal evidence from the Australian Longitudinal Study of Ageing. Psychology and Aging, 24(2), 296-309.

https://doi.org/10.1037/a0015069 
Gerstorf, D., Ram, N., Hoppmann, C., Willis, S. L., \& Schaie, K. W. (2011). Cohort differences in cognitive aging and terminal decline in the Seattle Longitudinal Study. Developmental Psychology, 47(4), 1026-1041. https://doi.org/10.1037/a0023426

Ghisletta, P., Rabbitt, P., Lunn, M., \& Lindenberger, U. (2012). Two thirds of the age-based changes in fluid and crystallized intelligence, perceptual speed, and memory in adulthood are shared. Intelligence, 40(3), 260-268. https://doi.org/10.1016/j.intell.2012.02.008

Gonzaga, G. C., Campos, B., \& Bradbury, T. (2007). Similarity, convergence, and relationship satisfaction in dating and married couples. Journal of Personality and Social Psychology, 93(1), 34-48. https://doi.org/10.1037/0022-3514.93.1.34

Gruber-Baldini, A., Warner Schaie, K., \& Willis, S. (1995). Similarity in married couples: A longitudinal study of mental abilities and rigidity-flexibility. Journal of Personality and Social Psychology, 69(1), 191-203.

Hale, J. M., Schneider, D. C., Mehta, N. K., \& Myrskylä, M. (2020). Cognitive impairment in the U.S.: Lifetime risk, age at onset, and years impaired. SSM - Population Health, 11, 100577. https://doi.org/10.1016/j.ssmph.2020.100577

Harris, C. B., Keil, P. G., Sutton, J., Barnier, A. J., \& McIlwain, D. J. F. (2011). We remember, we forget: Collaborative remembering in older couples. Discourse Processes, 48(4), 267303. https://doi.org/10.1080/0163853X.2010.541854

Hess, T. M., Auman, C., Colcombe, S. J., \& Rahhal, T. A. (2003). The impact of stereotype threat on age differences in memory performance. The Journals of Gerontology Series B: Psychological Sciences and Social Sciences, 58(1), P3-P11. https://doi.org/10.1093/geronb/58.1.P3 
Hu, L. \& Bentler, P. M. (1999). Cutoff criteria for fit indexes in covariance structure analysis: Conventional criteria versus new alternatives. Structural Equation Modeling, 6(1), 1-55.

Jajodia, A., \& Borders, A. (2011). Memory predicts changes in depressive symptoms in older adults: A bidirectional longitudinal analysis. The Journals of Gerontology Series B: Psychological Sciences and Social Sciences, 66B(5), 571-581. https://doi.org/10.1093/geronb/gbr035

Kenny, D. A., Kashy, D. A., Cook, W. L. (2006). Dyadic Data Analysis. New York: The Guilford Press.

Kim, Y., Kim, K., Boerner, K., \& Han, G. (2018). Aging together: Self-perceptions of aging and family experiences among Korean Baby Boomer couples. The Gerontologist, 58(6), 1044-1053. https://doi.org/10.1093/geront/gnx132

Kleinspehn-Ammerlahn, A., Kotter-Grühn, D., \& Smith, J. (2008). Self-perceptions of aging: Do subjective age and satisfaction with aging change during old age? The Journals of Gerontology: Series B, 63(6), P377-P385. https://doi.org/10.1093/geronb/63.6.P377

Kline, R. B. (2016). Principles and Practice of Structural Equation Modeling (4 ${ }^{\text {th }}$ ed.). The Guilford Press.

Kornadt, A. E., Hess, T. M., \& Rothermund, K. (2018). Domain-specific views on aging and preparation for age-related changes - Development and validation of three brief scales. The Journals of Gerontology: Series B. https://doi.org/10.1093/geronb/gby055

Lawton, M.P. (1975). The Philadelphia Geriatric Center Morale Scale: A revision. Journals of Gerontology, 30, 85-89. 
Levine, B., Svoboda, E., Hay, J. F., Winocur, G., \& Moscovitch, M. (2002). Aging and autobiographical memory: Dissociating episodic from semantic retrieval. Psychology and Aging, 17(4), 677-689. https://doi.org/10.1037/0882-7974.17.4.677

Levy, B. (1996). Improving memory in old age through implicit self-stereotyping. Journal of Personality and Social Psychology, 71(6), 1092-1107. https://doi.org/10.1037/0022$\underline{3514.71 .6 .1092}$

Levy, B. (2009). Stereotype embodiment: A psychosocial approach to aging. Current Directions in Psychological Science, 18(6), 332-336.

Levy, B. R., Ferrucci, L., Zonderman, A. B., Slade, M. D., Troncoso, J., \& Resnick, S. M. (2016). A culture-brain link: Negative age stereotypes predict Alzheimer's disease biomarkers. Psychology and Aging, 31(1), 82-88. https://doi.org/10.1037/pag0000062

Levy, B. R., \& Myers, L. M. (2004). Preventive health behaviors influenced by self-perceptions of aging. Preventive Medicine, 39(3), 625-629. https://doi.org/10.1016/j.ypmed.2004.02.029

Levy, B. R., Slade, M. D., Murphy, T. E., \& Gill, T. M. (2012). Association between positive age stereotypes and recovery from disability in older persons. JAMA: The Journal of the American Medical Association, 308(19), 1972-1973.

https://doi.org/10.1001/jama.2012.14541

Levy, B. R., Slade, M. D., Kunkel, S. R., \& Kasl, S. V. (2002). Longevity increased by positive self-perceptions of aging. Journal of Personality and Social Psychology, 83(2), 261-270.

Levy, B. R., Slade, M. D., Pietrzak, R. H., \& Ferrucci, L. (2018). Positive age beliefs protect against dementia even among elders with high-risk gene. PLOS ONE, 13(2), e0191004. https://doi.org/10.1371/journal.pone.0191004 
Levy, B. R., Zonderman, A. B., Slade, M. D., \& Ferrucci, L. (2012). Memory shaped by age stereotypes over time. The Journals of Gerontology Series B: Psychological Sciences and Social Sciences, 67(4), 432-436. https://doi.org/10.1093/geronb/gbr120

Lewis, N. A., Turiano, N. A., Payne, B. R., \& Hill, P. L. (2017). Purpose in life and cognitive functioning in adulthood. Aging, Neuropsychology, and Cognition, 24(6), 662-671. https://doi.org/10.1080/13825585.2016.1251549

Liang, J. \& Bollen, K. A. (1983). The structure of the Philadelphia Geriatric Center Morale scale: A reinterpretation. Journal of Gerontology, 38, 181-189. https://doi.org/10.1093/geronj/38.2.181

Lupien, S. J., McEwen, B. S., Gunnar, M. R., \& Heim, C. (2009). Effects of stress throughout the lifespan on the brain, behaviour and cognition. Nature Reviews Neuroscience, 10(6), 434-445. https://doi.org/10.1038/nrn2639

Margolis, R., \& Verdery, A. M. (2017). Older adults without close kin in the United States. The Journals of Gerontology: Series B, 72(4), 688-693. https://doi.org/10.1093/geronb/gbx068

McEwen, B. S. (2017). Neurobiological and systemic effects of chronic stress. Chronic Stress, 1. http://doi/10.1177/2470547017692328

Mejía, S. T., Giasson, H. L., Smith, J., \& Gonzalez, R. (2020). Concurrent and enduring associations between married partners' shared beliefs and markers of aging. Psychology and Aging. Advance online publication. https://doi.org/10.1037/pag0000515

Mejía, S. T., \& Gonzalez, R. (2017). Couples’ shared beliefs about aging and implications for future functional limitations. The Gerontologist, 57(suppl_2), S149-S159. https://doi.org/10.1093/geront/gnx071 
Miller, G. E., Chen, E., \& Zhou, E. S. (2007). If it goes up, must it come down? Chronic stress and the hypothalamic-pituitary-adrenocortical axis in humans. Psychological Bulletin, 133(1), 25-45. https://doi.org/10.1037/0033-2909.133.1.25

Momtaz, Y., Hamid, T. A., Masud, J., Haron, S. A., \& Ibrahim, R. (2013). Dyadic effects of attitude toward aging on psychological well-being of older Malaysian couples: An actorpartner interdependence model. Clinical Interventions in Aging, 1413. https://doi.org/10.2147/CIA.S51877

Monin, J., Doyle, M., Levy, B., Schulz, R., Fried, T., \& Kershaw, T. (2016). Spousal associations between frailty and depressive symptoms: Longitudinal findings from the Cardiovascular Health Study. Journal of the American Geriatrics Society, 64(4), 824830. https://doi.org/10.1111/jgs.14023

Muthén, L.K. and Muthén, B.O. (1998-2017). Mplus user's guide (8 $8^{\text {th }}$ ed.). Muthén \& Muthén.

Ofstedal, M. B., Fisher, G. G., Herzog, A. R. (2005) Documentation of Cognitive Functioning Measures in the Health and Retirement Study. Ann Arbor, Michigan: Institute for Social Research, University of Michigan. Retrieved from http://hrsonline.isr.umich.edu/sitedocs/userg/dr-006.pdf.

Oh, J., Chopik, W. J., \& Kim, E. S. (2019). The association between actor/partner optimism and cognitive functioning among older couples. Journal of Personality, jopy.12529. https://doi.org/10.1111/jopy.12529

Radloff, L. S. (1977). The CES-D scale: A self-report depression scale for research in the general population. Applied Psychological Measurement, 1(3), 385-401. 
Riley-Doucet, C. (2005). Beliefs about the controllability of pain: Congruence between older adults with cancer and their family caregivers. Journal of Family Nursing, 11(3), 225241. https://doi.org/10.1177/1074840705279157

Robertson, D. A., \& Kenny, R. A. (2016a). "I'm too old for that"-The association between negative perceptions of aging and disengagement in later life. Personality and Individual Differences, 100, 114-119. https://doi.org/10.1016/j.paid.2016.03.096

Robertson, D. A., \& Kenny, R. A. (2016b). Negative perceptions of aging modify the association between frailty and cognitive function in older adults. Personality and Individual Differences, 100, 120-125. https://doi.org/10.1016/j.paid.2015.12.010

Robertson, D. A., King-Kallimanis, B. L., \& Kenny, R. A. (2016). Negative perceptions of aging predict longitudinal decline in cognitive function. Psychology and Aging, 31(1), 71-81. https://doi.org/10.1037/pag0000061

Rusbult, C. E., \& Van Lange, P. A. M. (2003). Interdependence, interaction, and relationships. Annual Review of Psychology, 54(1), 351-375. https://doi.org/10.1146/annurev.psych.54.101601.145059

Sargent-Cox, K. A., Anstey, K. J., \& Luszcz, M. A. (2012). Change in health and selfperceptions of aging over 16 years: The role of psychological resources. Health Psychology, 31(4), 423-432. https://doi.org/10.1037/a0027464

Seefeldt, C., Jantz, R. K., Galper, A., \& Serock, K. (1977). Using pictures to explore children's attitudes toward the elderly. The Gerontologist, 17(6), 506-512. https://doi.org/10.1093/geront/17.6.506 
Siebert, J. S., Braun, T., \& Wahl, H.-W. (2020). Change in attitudes toward aging: Cognitive complaints matter more than objective performance. Psychology and Aging, 35(3), 357368. https://doi.org/10.1037/pag0000451

Sindi, S., Juster, R.-P., Wan, N., Nair, N. P. V., Ying Kin, N., \& Lupien, S. J. (2012). Depressive symptoms, cortisol, and cognition during human aging: The role of negative aging perceptions. Stress, 15(2), 130-137. https://doi.org/10.3109/10253890.2011.599047

Smith, J., \& Larkina, M. (2020). Early-life health as a lifelong precursor of self-related views of aging in later life. The Journals of Gerontology: Series B. https://doi.org/10.1093/geronb/gbaa141

Smith, J., Ryan, L. H., Fisher, G. G., Sonnega, A., \& Weir, D. R. (2017). HRS psychosocial and lifestyle questionnaire 2006-2016. Ann Arbor, MI: Survey Research Center, Institute for Social Research, University of Michigan. Retrieved from https://hrs.isr.umich.edu/sites/default/files/biblio/HRS\%2020062016\%20SAQ\%20Documentation_07.06.17_0.pdf.

St-Laurent, M., Abdi, H., Burianová, H., \& Grady, C. L. (2011). Influence of aging on the neural correlates of autobiographical, episodic, and semantic memory retrieval. Journal of Cognitive Neuroscience, 23(12), 4150-4163. https://doi.org/10.1162/jocn_a_00079

Stancanelli, E., \& Van Soest, A. (2016). Partners' leisure time truly together upon retirement. IZA Journal of Labor Policy, 5(1), 12. https://doi.org/10.1186/s40173-016-0068-7

Stavrova, O. (2019). Having a happy spouse is associated with lowered risk of mortality. Psychological Science, 30(5), 798-803. https://doi.org/10.1177/0956797619835147

Steverink, N., Westerhof, G. J., Bode, C., \& Dittmann-Kohli, F. (2001). The personal experience of aging, individual resources, and subjective well-being. The Journals of Gerontology 
Series B: Psychological Sciences and Social Sciences, 56(6), P364-P373. https://doi.org/10.1093/geronb/56.6.P364

Strawbridge, W. J., Wallhagen, M. I., \& Shema, S. J. (2011). Spousal interrelations in selfreports of cognition in the context of marital problems. Gerontology, 57(2), 148-152. https://doi.org/10.1159/000318637

Tovel, H., Carmel, S., \& Raveis, V. H. (2019). Relationships among self-perception of aging, physical functioning, and self-efficacy in late life. The Journals of Gerontology: Series B, 74(2), 212-221. https://doi.org/10.1093/geronb/gbx056

U.S. Census Bureau (2010). America's families and living arrangements, table A1: Marital status of people 15 years and over, by age, sex, personal earnings, race, and Hispanic origin. Retrieved from https://www.census.gov/population/www/socdemo/hh-fam/cps2010.html.

Walker, R. B., \& Luszcz, M. A. (2009). The health and relationship dynamics of late-life couples: A systematic review of the literature. Ageing and Society, 29(3), 455-480. https://doi.org/10.1017/S0144686X08007903

Wilson, R. S., Wang, T., Yu, L., Bennett, D. A., \& Boyle, P. A. (2020). normative cognitive decline in old age. Annals of Neurology, 87(6), 816-829. https://doi.org/10.1002/ana.25711

Zank, S., \& Leipold, B. (2001). The relationship between severity of dementia and subjective well-being. Aging \& Mental Health, 5(2), 191-196.

\section{https://doi.org/10.1080/13607860120038375}

Zhang, F., Fung, H., \& Kwok, T. (2019). Spouse's subjective social status predicts older adults' prospective cognitive functioning. Aging \& Mental Health, 23(2), 277-285. https://doi.org/10.1080/13607863.2017.1406449 


\section{APPENDIX A: FIGURES AND TABLES}

\section{Figure 1}

Actor-Partner Interdependence Model

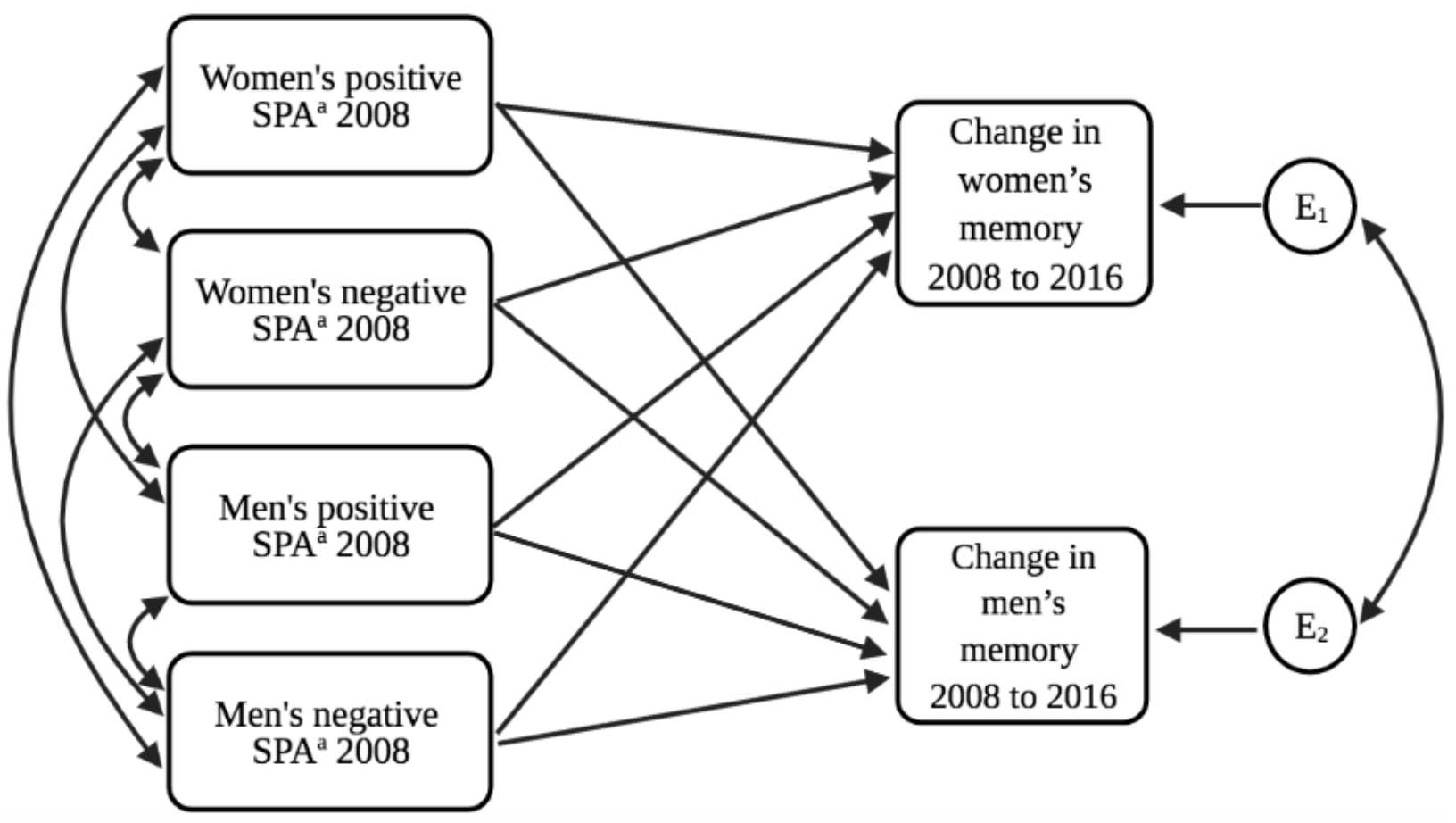

Note. This figure was adapted from Kenny et al. (2006) and created in BioRender.com.

Covariates were age, education, race, ethnicity, financial assets, self-rated health, and depressive symptoms.

${ }^{\text {aSPA }}=$ self-perceptions of aging. 


\section{Table 1}

Participant Demographic Characteristics

\begin{tabular}{lccc}
\hline & Men & Women & \\
\cline { 2 - 4 } & $M(S D)$ or $\%$ & $M(S D)$ or $\%$ & $t$ \\
\cline { 2 - 4 } Age (in years) & $66.77(7.79)$ & $63.97(7.67)$ & $18.59 * * *$ \\
Education (in years) & $13.23(3.23)$ & $13.05(2.86)$ & $2.05^{*}$ \\
Self-rated health & $3.40(1.01)$ & $3.47(0.98)$ & -1.70 \\
Depressive symptoms & $0.79(1.39)$ & $0.95(1.59)$ & $-2.51^{*}$ \\
Positive SPA & $4.49(1.17)$ & $4.50(1.22)$ & -0.25 \\
Negative SPA & $3.13(1.21)$ & $2.97(1.22)$ & $0.34 * *$ \\
Self-rated memory T1 & $3.09(0.93)$ & $3.10(0.87)$ & -0.17 \\
Self-rated memory T2 & $2.83(0.93)$ & $2.91(0.89)$ & -1.77 \\
Episodic memory T1 & $9.94(2.94)$ & $11.38(2.92)$ & $-11.55^{* * *}$ \\
Episodic memory T2 & $8.69(3.17)$ & $10.19(3.05)$ & $-11.40^{* * *}$ \\
\hline Note. $n=933$. & & & \\
\hline
\end{tabular}

Note. $n=933$.

${ }^{\text {a }}$ Married $n=908$. ${ }^{\mathrm{S}} \mathrm{SPA}=$ self-perceptions of aging.

$* p<.05, * * p<.01, * * * p<.001$ 


\section{Table 2}

Correlations Between Self-Perceptions of Aging, Episodic Memory, and Self-Rated Memory

$$
\begin{aligned}
& \text { Variables } \\
& \text { tive self-perceptions of aging } \\
& \text { omen } \\
& .27 * * *
\end{aligned}
$$

Negative self-perceptions of aging
3. Men
$-.44 * * * \quad-.19 * * *$
4. Women
$-.17 * * * \quad-.44 * * *$
$.23 * * *$

\section{Episodic memory T1}

5. Men

6. Women

Episodic memory T2

7. Men

8. Women

\section{Self-rated memory $\mathbf{T 1}$}

9. Men

$.16^{* * *}$

10. Women

.05

.04

.06

.05

.01

.03

Self-rated memory T2

.05

.03
.06

$.10 * * *$

$.16 * * *$

$-.28 * * *$

$-.11 * * *$

$-.14 * * *$

$-.28 * * *$

$.22 * * *$

$.10 * *$

$.14 * * *$

.06

$.14 * * *$

$.21 * * *$

$.55 * * *$

$.17 * * * \quad .55 * * *$

$-.21 * * * \quad-.04$

$-.12 * * * \quad-.25 * * *$
$.20 * * *$

$.08^{*}$
12. Women
$* p<.05, * * p<.01, * * * p<.001$. 
Table 2

Continued

$\begin{array}{llllll}\text { Variables } & 7 & 8 & 9 & 10 & 11\end{array}$

\section{Episodic memory T2}

7. Men

8. Women

$.22 * * *$

Self-rated memory $\mathbf{T 1}$

9. Men

$.19 * * * \quad .10 * * *$

10. Women

$.10 * * * \quad .24 * * * \quad .16 * * *$

\section{Self-rated memory T2}

$\begin{array}{llllll}11 . \text { Men } & .27 * * * & .08 * & .53 * * * & .12 * * * & \\ 12 . \text { Women } & .09 * & .22 * * * & .09 * * & .55 * * * & .13 * * *\end{array}$

$* p<.05, * * p<.01, * * * p<.001$. 


\section{Table 3}

Results of Actor-Partner Interdependence Models

\begin{tabular}{|c|c|c|c|c|c|c|c|c|}
\hline & \multicolumn{4}{|c|}{ Episodic memory } & \multicolumn{4}{|c|}{ Self-rated memory ${ }^{a}$} \\
\hline & \multicolumn{2}{|c|}{ Men } & \multicolumn{2}{|c|}{ Women } & \multicolumn{2}{|c|}{ Men } & \multicolumn{2}{|c|}{ Women } \\
\hline & $B$ & $S E$ & $B$ & $S E$ & $B$ & $S E$ & $B$ & $S E$ \\
\hline Intercept & -1.22 & 1.42 & -2.22 & 1.33 & .31 & .47 & .23 & .47 \\
\hline \multicolumn{9}{|l|}{$\begin{array}{l}\text { Positive SPA } \\
\text { (range } 1-6)^{\mathrm{b}}\end{array}$} \\
\hline Own & .10 & .10 & -.05 & .09 & -.01 & .03 & -.02 & .03 \\
\hline Partner's & -.04 & .09 & .00 & .09 & .01 & .03 & .01 & .03 \\
\hline \multicolumn{9}{|l|}{$\begin{array}{l}\text { Negative SPA } \\
\text { (range 1-6) }\end{array}$} \\
\hline Own & -.07 & .10 & -.05 & .09 & -.04 & .04 & .02 & .03 \\
\hline Partner's & .09 & .09 & .01 & .09 & -.03 & .03 & -.01 & .03 \\
\hline \multicolumn{9}{|l|}{ Covariates } \\
\hline Age (years) & $.05^{* *}$ & .01 & $.06 * * *$ & .01 & .00 & .00 & .00 & .00 \\
\hline $\begin{array}{l}\text { Education } \\
\text { (years) }\end{array}$ & -.01 & .04 & -.01 & .04 & -.01 & .01 & -.02 & .01 \\
\hline \multicolumn{9}{|l|}{ Race $^{\mathrm{c}}$} \\
\hline Black & -.17 & .37 & .55 & .40 & .13 & .14 & .05 & .11 \\
\hline Other & .08 & .47 & -.74 & .41 & -.07 & .12 & .03 & .16 \\
\hline Ethnicity $^{\mathrm{d}}$ & -.55 & .37 & .14 & .36 & -.18 & .12 & -.03 & .12 \\
\hline \multicolumn{9}{|l|}{ Wealth ${ }^{e}$} \\
\hline $\begin{array}{l}1^{\text {st }} \text { quintile } \\
\text { (lowest) }\end{array}$ & -.61 & .35 & -.21 & .32 & .18 & .11 & -.08 & .10 \\
\hline $2^{\text {nd }}$ quintile & -.54 & .32 & -.15 & .30 & -.11 & .09 & -.19 & .09 \\
\hline $3^{\text {rd }}$ quintile & -.68 & .31 & .35 & .31 & -.09 & .10 & -.08 & .09 \\
\hline $4^{\text {th }}$ quintile & -.56 & .32 & .17 & .32 & -.16 & .09 & -.21 & .09 \\
\hline $\begin{array}{l}\text { Self-rated } \\
\text { health }^{\mathrm{a}}\end{array}$ & -.12 & .11 & .10 & .12 & .08 & .04 & $.13 * * *$ & .04 \\
\hline $\begin{array}{l}\text { Depressive } \\
\text { symptoms }{ }^{\mathrm{f}}\end{array}$ & -.01 & .08 & .08 & .07 & -.04 & .03 & -.02 & .02 \\
\hline $\begin{array}{l}\text { Residual } \\
\text { variance }\end{array}$ & $7.71 * * *$ & .44 & $7.72 * * *$ & .41 & $.79 * * *$ & .05 & $.68 * * *$ & .04 \\
\hline
\end{tabular}

Note. Couple $N=933$.

${ }^{\text {a Higher }}=$ better. ${ }^{\mathrm{b}} \mathrm{SPA}=$ self-perceptions of aging. ${ }^{\mathrm{c}}$ White $=$ reference group. ${ }^{\mathrm{d}}$ non-Hispanic $=$

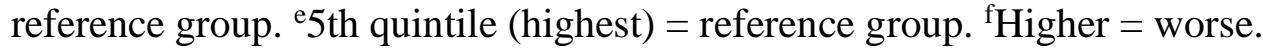

$* p<.05, * * p<.01, * * * p<.001$ 